\title{
LINKAGE STUDIES ON THE MUTANT SHORT-WING IN THE MOSQUITO AEDES AEGYPTI
}

\author{
A. M. PEARSON* \\ Department of Zoology, University of Manchester, U.K.
}

Received 20.xii.79

\begin{abstract}
SUMmaRY
A study of recombination between the recessive mutant short-wing $(s w)$ and the sex-locus in Aedes aegypti revealed a greater number of female $(\mathrm{m} / \mathrm{m})$ than male $(M / m)$ recombinants in the test-cross: $+M / s w \sigma^{t} \times s w ~ m / s w ~ m$ o . In both sexes, but more particularly in the female, the frequency of recombinants was seen to increase over a number of generations of laboratory culture. In three substrains of short wing fixed for different eye colours, one showed a significantly increased number of female recombinants compared with the base strain and the two other substrains. Three-point test-crosses between $M$, sw, and $w$ (or $r e$ ) showed the $s w$ locus to be positioned between $M$ and $w$, near $b z$.
\end{abstract}

\section{InTRODUCTION}

THE spontaneous recessive mutant short-wing ( $s w$ ) in Aedes aegypti was shown by Uppal et al. (1976) to be very closely linked to the sex-locus $M / m$; male and female recombinants were recovered at a frequency of $<1$ per cent when $s w \mathrm{~m} / \mathrm{sw} m$ females were mass mated to $+M / s w m$ males. Further studies on recombination have now been made during the maintenance of the strain at Manchester University.

\section{Materials and Methods}

The two strains used in the investigation were:

short-wing: derived by Uppal et al. (1976) from back-crosses of the JY multiple marker stock with ROCK background to the Delhi wild-type strain; supplied by WHO, and colonised in Manchester in 1975.

Papeete: a wild-type stock originating from Tahiti Island; supplied by $\mathrm{Dr}$ Rivière, and colonised in Manchester in 1976.

The short-wing strain was maintained in the way described by Uppal et al. (1976), by crossing sw $\mathrm{m} / \mathrm{sw} m$ females and $+M / s w ~ m$ males. Adults were scored for presence/absence of the short-wing phenotype at each generation, so that any recombinants $(s w / s w o t,+/ s w$ o $)$ could be removed.

Recombination between $M$ and sw was studied in the original strain for nine generations. Then from this strain, three new substrains were created fixed for a different eye colour gene: red eye $(r e)$, white eye $(w)$ and wildtype $(+)$. The original strain was polymorphic for these genes. The new lines were produced by mass mating at least 25 males with 25 females.

\footnotetext{
* Present address: Department of Genetics, University of Leeds, U.K.
} 
Selection was carried out for a number of generations in the + strain to remove $r e$ and $w$ segregants. Recombination was studied in the new substrains for five generations (seven in the white eyed stock).

The position of sw on linkage group 1 (the sex-chromosomes) was determined by two three-point test-crosses. In the first of these red-eyed, shortwing females were mass mated to wild-type (Papeete) males, and the heterozygous $F_{1}$ males back-crossed to the female parental type, in 10 single pairs. In the second, the procedure was repeated with white-eyed, shortwing females, the gene for white eye $(w)$ being on the opposite side of the $M / m$ locus to the red eye gene $(r e)$ (Craig \& Hickey, 1967).

\section{RESUlts}

The percentage of female recombinants recovered from the original strain over nine generations ( 4.7 per cent, table $1(a)$ ) was significantly higher than that for male recombinants $\left(0.4\right.$ per cent, $\chi^{2}=103 \cdot 18, \mathrm{P}<$ $0.001)$. Figure 1 shows that the frequency of recombinants increased over the period of study; this increase was significant in the female data $(\mathrm{F}=$ $6.76, \mathrm{P}<0.05)$, but not in the male data. The total data showed a highly significant increase $(F=21.86, P<0.001)$. However, as the male and female regression slopes were significantly different $(t=12.67, P<0.001)$, the regression slope for the pooled data is given no further consideration.

\section{TABLE 1}

Mean rate of recombination between $\mathrm{sw}$ and $\mathrm{M}$ in crosses betzeen $+\mathrm{M} / \mathrm{sw} \mathrm{m}$ males and $\mathrm{sw} \mathrm{m} / \mathrm{sw} \mathrm{m}$ females in (a) the original short-wing strain polymorphic for eye colour and (b) three substrains: wild-type $(+)$, red (re), and white $(\mathrm{w})$ eye colours

\begin{tabular}{|c|c|c|c|c|c|c|c|}
\hline Stock & Generations & $\begin{array}{c}\text { No. male } \\
\text { progeny }\end{array}$ & $\begin{array}{c}\% \text { male } \\
\text { recombin- } \\
\text { ants } \\
(s w / s w)\end{array}$ & $\begin{array}{c}\text { No. female } \\
\text { progeny }\end{array}$ & $\begin{array}{c}\% \text { female } \\
\text { recombin- } \\
\text { ants } \\
(+/ s w)\end{array}$ & $\begin{array}{c}\text { Total } \\
\text { progeny }\end{array}$ & $\begin{array}{l}\text { Total } \% \\
\text { recombin- } \\
\text { ants }\end{array}$ \\
\hline & $1-9$ & 2369 & $0 \cdot 4 \pm 0 \cdot 1$ & & $4.7 \pm 0.5$ & & \\
\hline+ & $1-5$ & & $0 \cdot 6 \pm 0 \cdot 4$ & 229 & $\begin{array}{c}0.9 \pm 1.3 \\
14.4 \pm 2 \cdot 3\end{array}$ & 563 & $\begin{array}{l}3 \cdot 7 \pm \\
6 \cdot 2 \pm\end{array}$ \\
\hline$r e$ & $1-5$ & 718 & $1 \cdot 0 \pm 0.3$ & 520 & $4.4 \pm 0.9$ & 1238 & $2 \cdot 4 \pm 0.4$ \\
\hline$w$ & $1-7$ & 1057 & $1 \cdot 2 \pm 0 \cdot 3$ & 998 & $5.8 \pm 0.7$ & 2055 & $3.5 \pm 0.4$ \\
\hline
\end{tabular}

After the creation of short-wing substrains with different eye colours, all three substrains gave significantly fewer male than female recombinants (table $1(b), w, \chi^{2}=32.31, \mathrm{P}<0.001 ; r e, \chi^{2}=15 \cdot 16, \mathrm{P}<0.001 ;+, \chi^{2}=$ $44.45, \mathrm{P}<0.001)$. The red eye and white eye substrains showed similar levels of recombination to the original strain (generations 1-9) but slightly fewer female recombinants than in generations 8 and $9\left(w, \chi^{2}=0.61\right.$, $\left.\mathrm{P}>0.05 ; r e, \chi^{2}=2 \cdot 71, \mathrm{P}>0.05\right)$. The recovery of female recombinants in the wild-type substrain was significantly higher than in the other two substrains $\left(+: w, \chi^{2}=20.06, \mathrm{P}<0.001 ;+: r e, \chi^{2}=22.92, \mathrm{P}<0.001\right)$, and also significantly higher than the base strain $\left(\chi^{2}=9.45, \mathrm{P}<0.01\right)$.

There was no significant change in frequency of recombinants in any of the three substrains over the 5-7 generations studied, in contrast to that seen in the original strain.

The data from the three-point test-crosses, and the position of sw on the 


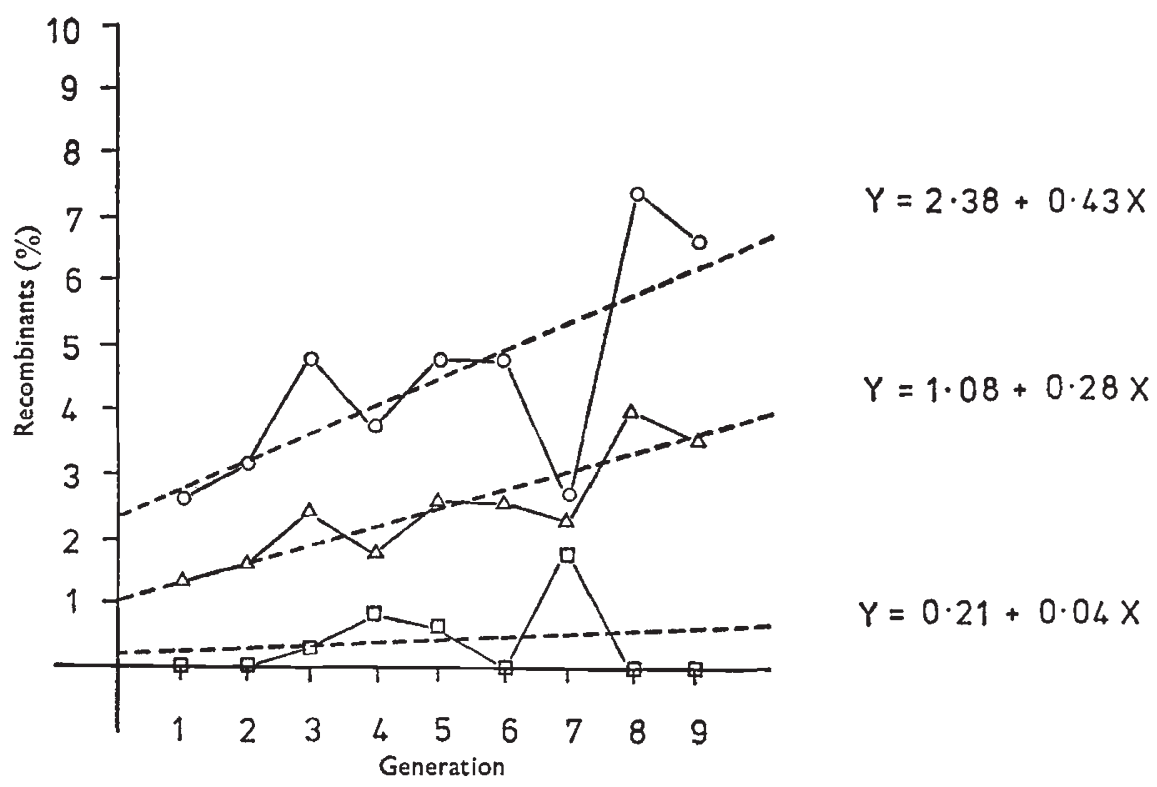

Fig. 1.-Change in frequency of recovery of recombinants in the short-wing stock.

$O=$ female progeny; $\square=$ male progeny; $\Delta=$ total progeny

\section{TABLE 2}

Position of sw on sex-chromosome, as determined by three-point test-crosses

(a) cross: re sw $m / r e s w m$ 우 $\times$ re sw $m /++M$ 추

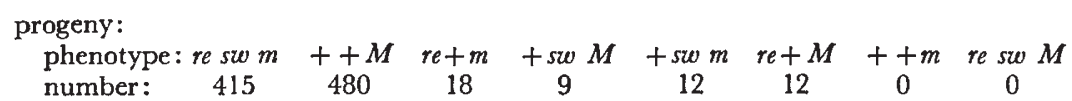

(b) cross: $w$ sw $m / w s w m$ ㅇ $\times w s w m /++M$ क

progeny:

phenotype: $w$ sw $m++M w+m+s w M+s w m w+M++m$ w $w M$ $\begin{array}{lllllllll}\text { number: } & 91 & 114 & 0 & 0 & 15 & 16 & 4 & 0\end{array}$

(c) linkage map: $\begin{aligned} 2.5 & \stackrel{2.9}{\frac{1.7}{\longrightarrow}} s w-\cdots \cdots \cdots \cdots-w \\ \longleftarrow & \end{aligned}$

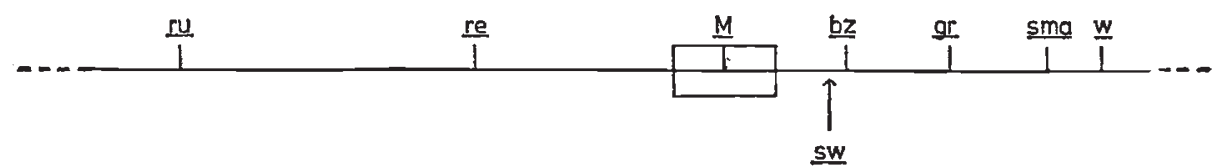

Fig. 2-Location of $s w$ on linkage group 1*.

* positions of other loci obtained from Bhalla + Craig (1970). 
sex-chromosome in relation to $r e, M$, and $w$, are given in table 2 . In fig. 2 the position of sw on linkage group 1 is related to the map published by Bhalla and Craig (1970).

\section{Discussion}

Recombination between sw and $M$ can only be estimated in the male. Uppal et al. (1976), the first to study the linkage between these two markers, found fewer than 1 per cent recombinants of either sex after test-crossing to double recessive females. The test-crosses reported in this paper produced a similarly low proportion of male recombinants. However, the recovery of female recombinants was consistently greater and, moreover, increased significantly during the nine generations of study.

The difference in recovery of male and female recombinants can be explained if the sw/sw homozygote is of a reduced viability. (The survival and fecundity of $s w \mathrm{~m} / \mathrm{sw} \mathrm{m}$ was found to be low in a study made by Uppal et al., 1976.) The mean viability of the $s w / s w$ adults (no. of $s w / s w$ adults $\div$ no. of $+/ s w$ adults in $\mathbf{F}_{1}$ from sw $\left.\mathrm{m} / \mathrm{sw} m q \times+M / s w m^{\gamma}\right)$ was estimated in the present study at $0.86\left(\chi^{2}=28.52, \mathrm{P}<0.001\right)$. However, the total number of males scored was greater than the number of females scored, making this estimate a little too high. The male " recombinants" from this test-cross would be homozygous for the recessive mutant (sw $M / s w m$ ), and hence would be expected to show a lower recovery rate than the male "parentals", which would be heterozygous for the wild-type $(+M / s w m)$. It follows that the actual degree of recombination between $M$ and sw was greater than 0.4 per cent (recovery of male recombinants). Equally, the actual degree of recombination was less than $4 \cdot 7$ per cent (recovery of female recombinants) if sw $\mathrm{m} / \mathrm{sw} m$ "parental" female homozygotes showed reduced viability in comparison with the $+m / s w$ " recombinant" females. The mean percentage recombination over the nine generations for the male and female progeny combined was 2.5 per cent. This is a more realistic figure for the recombination rate, as differential viability of recombinant classes should not affect the result for the total data (Bailey, 1961).

The increase in the recovery of recombinants which occurred in the original strain during the period of study could be explained by selection for increased viability of the female heterozygote. It is also possible that there was a rearrangement of genetic material, possibly the loss of an inversion. The high rate of recombination between sw and $M$ in the wild-type eye

TABLE 3

Linkage distances in chromosome 1: a compilation of published data

data source
Macdonald and Sheppard
McClelland (1966)
Hickey and Craig (1966)
Bhalla (1968)
Bhalla (1970)
Bhalla and Craig (1970)
Petersen et al. $(1976)$

Petersen et al. (1976)

\begin{tabular}{cc}
\multicolumn{2}{c}{$\%$ recombination } \\
$M-w$ & $M-r e$ \\
- & $2 \cdot 1,5 \cdot 7$ \\
- & $6 \cdot 4$ \\
- & $7 \cdot 8,1 \cdot 0$ \\
$17 \cdot 4$ & - \\
$15 \cdot 0$ & $7 \cdot 5$ \\
$14 \cdot 4$ & $7 \cdot 2,8 \cdot 4$ \\
$13-18$ & 4
\end{tabular}


substrain compared with the $w$ and re substrains might suggest an inversion associated with these eye mutant genes which is not found in the wild-type. Since the wild-type eyed adult is likely to be more competitive than mutant eye phenotypes, then its preferential selection in the initial stock would explain the increase in recombination seen in fig. 1. However, the evidence can also be used to support the idea that the wild-type $+/ s w$ female has a higher viability than the red or white eyed $+/ s w$ females. Studies are at present being carried out to investigate any correlation between frequency of the wild-type eye phenotype and recombination rate over a number of generations in a mixed eye colour strain of short-wing. The viability of the $+/ s w$ heterozygotes in the three substrains is also being studied.

The test-crosses to determine the position of sw on linkage group 1 placed it between $M$ and $b z$ (bronze) on the arm bearing $w$ (fig. 2). The estimated recombination between $M$ and $w(14.7$ per cent) was similar to that recorded by Bhalla (1970) and Bhalla and Craig (1970) (table 3); that between $M$ and $r e(2.5$ per cent) was lower than most, but not all, previous estimates.

Acknowledgments.-My thanks to Dr R. J. Wood for his helpful ideas and constructive criticism of the document in typescript; also to $\mathrm{Mr} \mathrm{A}$. Whitelaw for his technical help.

\section{REFERENCES}

BAILEY, N. T. J. 1961. Introduction to the Mathematical Theory of Genetic Linkage. Clarendon Press, Oxford.

BHALlA, s. G. 1968. White-eye-a new sex-linked mutant of Aedes aegypti. Mosquito Nert's, $28,380-385$.

BHALl. , s. C. 1970. Paracentric inversions and the detection of sex-linked recessive lethals in Aedes aegypti. Can. 7. Genet. Cytol., 12, 635-650.

BHALlA, s. G., AND GRAIG, G. B. 1970. Linkage analysis of chromosome of Aedes aegypti. Can. J. Genet. Cytol., 12, 425-435.

GRAIG, G. B., AND HICKEY, w. A. 1967. Genetics of Aedes aegypti, in Genetics of Insect Vectors of Disease, eds. J. W. Wright and R. Pal, pp. 67-131. Elsevier, Amsterdam.

HICKEY, W. A. AND CRAIG, G. B. 1966. Genetic distortion of sex-ratio in a mosquito, Aedes aegypti. Genetics, 53, 1177-1196.

MACDONALD, w. W. AND SHEPPARD, P. M. 1965. Crossover values in the sex-chromosomes of the mosquito Aedes aegypti and evidence of the presence of inversions. Ann. trop. Med. Parasit., 59, 74-87.

MCCLelland, G. A. H. 1966. Sex-linkage at two loci affecting eye pigment in the mosquito Aedes aegypti. Can. 7. Genet. Cytol., 8, 192-198.

PETERSEN, J. L., LARSEN, J. R. AND GRAig, G. B. 1976. Palp-antennae: a homeotic mutant in Aedes aegypti. 7. Hered., 67, 71-78.

UPPAL, D. K., CURTIS, C. F., AND SONI, K. v. 1976. A new sex-linked mutant short wing in Aedes aegypti. Heredity, 36, 147-150. 